\title{
Effects of Valine and Leucine on Some Antioxidant Enzymes in Hypercholesterolemic Rats
}

\author{
Elena Cojocaru1, Nina Filip ${ }^{2 *}$, Carmen Ungureanu1, Cristiana Filip², Mihai Danciu1 \\ ${ }^{1}$ Department of Pathology, University of Medicine and Pharmacy “Gr. T. Popa”, Iasi, Romania \\ ${ }^{2}$ Department of Biochemistry, University of Medicine and Pharmacy "Gr. T. Popa", Iasi, Romania \\ Email: ${ }^{*}$ zamosteanu_nina@yahoo.com
}

Received 12 July 2014; revised 31 August 2014; accepted 17 September 2014

Academic Editors: Ivan Sosa, Department of Forensic Medicine and Criminalistics, University of Rijeka Medical Faculty, Croatia; Elena Albu, Department of Pharmacology, “Gr.T. Popa” University of Medicine and Pharmacy, Romania

Copyright (C) 2014 by authors and Scientific Research Publishing Inc.

This work is licensed under the Creative Commons Attribution International License (CC BY).

http://creativecommons.org/licenses/by/4.0/

(c) () Open Access

\section{Abstract}

Objective: Reactive oxygen species (ROS) are involved in the endothelial-mediated disorders within atherosclerosis. Considering that an oxidant/antioxidant imbalance might be a key factor in the damaging ROS-mediated effects, the present study intends to determine the influence of a high-fat diet, associated with essential amino acids-valine and leucine, upon the experimental animals, through evaluation of plasmatic level of some antioxidant enzymes. Material and Methods: The study was conducted on 32 male Wistar rats, which were fed with cholesterol, valine and leucine, for 60 days. The animals were divided into four groups, according to the received diet: the first group-standard diet; the second group-cholesterol (C); the third group-cholesterol and valine $(C+V)$; the fourth group-cholesterol and leucine $(C+L)$. Evaluations of the oxidative status, through plasma levels of the antioxidant enzymes: superoxide dismutase (SOD) and glutathione peroxidise (GPx), were made for the four mentioned groups of animals, at the beginning of the study (R0), after one (R1) and two months (R2). Results: The average values of SOD and GPX in group of animals fed exclusively with cholesterol (C) were significantly higher compared to the third group where cholesterol was supplemented with valine $(C+V)$ or fourth group fed with cholesterol and leucine $(C+L)(p<0.001)$, after one month as well at the end of the experiment (two months). There were no significant differences in the levels of SOD and GPx between group III and group IV $(p<0.05)$ at the end of the experiment. Conclusion: Our results showed that valine and leucine decreased the serum levels of SOD and GPX and therefore they were useful antioxidants,

*Corresponding author.

How to cite this paper: Cojocaru, E., Filip, N., Ungureanu, C., Filip, C. and Danciu, M. (2014) Effects of Valine and Leucine on Some Antioxidant Enzymes in Hypercholesterolemic Rats. Health, 6, 2313-2321. 
which could improve the endothelial dysfunctions associated with atherosclerosis. Moreover, analysis of the oxidative status in the context of atherosclerotic mediated endothelial damage suggests that deviation from normal to alter endothelial status may be conditioned by an oxidants/antioxidants imbalance.

\section{Keywords}

\section{Valine, Leucine, SOD, GPx, Atherosclerosis}

\section{Introduction}

Atherosclerosis is considered a progressive disorder which initially induces a number of endothelial dysfunctions of the vascular wall that are currently perceived by an increasing number of experts as the key event of the inflammatory process preceding the atherosclerotic plaque. Inflammation generates an oxidative environment which triggers different events starting from lipid oxidation to protein oxidation and the formation and release of species involved in cellular signaling [1] [2]. Recent data suggest the discovery of new chemokine biomarkers involved in atherosclerosis prevention and its early detection. These new markers chemokines activate leukocytes and are known in the environment of inflammatory response [3].

The fragile balance between NO (nitric oxide) and ROS (reactive oxygen species) is specifically important in maintenance of a normal endothelial function, and any slight imbalance between these components resulting in oxidative insult [4]. Reactive oxygen species are actively involved in cellular and molecular processes related to the transition from fatty streaks to more complicated lesions in atherosclerosis [5] [6]. They directly inactivate NO, acting as signal molecules which promote protein dysfunction, contributing to the initiation of atherosclerosis. Therefore it is understandable that the special interest for any compound could firstly limit the vascular reactive oxygen species production and restore the endothelial function in patients with vascular complications [7].

Our experimental study aimed to investigate the potential of improvement and prevention of the atherosclerotic process development by dietary supplementation with essential amino acids that could influence some risk factors, particularly by addition of two branched amino acids. Based on our previous observations which suggest that valine and leucine modulate the turnover of serum HDL-cholesterol levels, a well-known lipoprotein associated to the lowering of cardiovascular risk, we focused our attention toward these two essential amino acids that could improve clinical conditions associated with hyperlipidemia [8]. This paper presents only the results of the biochemical study; the histological results will be presented in another article.

\section{Material and Methods}

The experimental study was designed over a period of 60 days. We used adult Wistar male rats, $250-280 \mathrm{~g}$ weight range, provided by animal research division of the University of Medicine and Pharmacy, "Gr. T. Popa" Iasi. During the experiment the guide's instructions on care and use of animals for scientific purposes were followed [9]. Rats were distributed into 4 groups, 8 rats each, fed as per the following: group I—control standard diet, group II—cholesterol $0.4 \mathrm{~g} / \mathrm{kgc} /$ day (C), group III—cholesterol $0.4 \mathrm{~g} / \mathrm{kgc} /$ day and valine $62.5 \mathrm{mg} / \mathrm{kgc} / \mathrm{day}$ $(\mathrm{C}+\mathrm{V})$, group IV—cholesterol $0.4 \mathrm{~g} / \mathrm{kgc} /$ day and leucine $69.985 \mathrm{mg} / \mathrm{kgc} / \mathrm{day}(\mathrm{C}+\mathrm{L})$. At the beginning of the experiment (R0), after 30 days (R1) and at the end of the experiment (R3), we collected blood samples from retro-orbitary plexus of each animal in order to determine the blood levels of SOD and GPx activities.

GPx assay was performed using Ransel GPx kit, according to the manufacturer protocol, SOD being assayed using the Ransod kit, and the results read on a spectrophotometer Cobas 6000 model.

Estimation of superoxide dismutase in the blood samples was done according to the method of Woolliams J. A. et al. [10]. The superoxide dismutase activity is represented by the degree of inhibition of this reaction. One unit of SOD is that which determines a 50\% inhibition of the rate of the reduction of INT under the assay conditions.

Assay of Glutathione Peroxidase (GPx) in the blood samples was done according to the Paglia and Valentine method using Randox kit [11].

Statistical analysis: The obtained data was introduced into statistical package for social sciences (SPSS) version 12 software and was analyzed using appropriate statistical functions (student's independent samples $t$-test). 
The data are expressed as mean \pm SD. The Chi square values and $\mathrm{p}$ values are used for the interpretation of results. P value $<0.05$ is considered as significant.

\section{Results}

The evolution and the variation of SOD values during the experiment were as follows: in group I (control), the most homogeneous set of values was registered at the beginning of the experiment (13.08 CV\%—coefficient of variance). The variance of values in groups II, III and IV was between 5.28 to $13.32 \mathrm{CV} \%$, and the most homogeneous set of values was recorded at the end of the experiment in all of the groups II (C) (5.28 CV\%), III (C + V) (12.03 CV\%) and IV (C + L) (11.57 CV\%) (Figure 1).

The highest individual SOD values were recorded in group II, fed by only cholesterol (Figure 1).

The average values of SOD, according to the moment of the investigation, revealed the following percentage elevations (Figure 2):

In group II, the percentage increase in average SOD values after one and two months was $38.5 \%$, and $50.2 \%$ respectively, in group III the average increase was of $2.1 \%$ and $3.6 \%$ (after one and two months), while group IV recorded increases of about $3.6 \%$ and $5.3 \%$ after one and two months, respectively. No significant differences between mean SOD values were recorded within study groups or between them and the control group, at the beginning of the study (R0) ( $\mathrm{p}>0.05)$. Group II registered increased mean SOD values compared to control at one and two months from the beginning of the experiment $(\mathrm{p}<0.001)$. Moreover, both after one month, and at the end of the experimental period, mean values of the group II were significantly higher compared to groups of rats with meals supplemented by essential amino acids: III $(C+V)$ and IV $(C+L)(p<0.001)$. Comparing the supplemented groups, after sixty days, average SOD values in group III supplemented with valine did not differ significantly from group IV that received leucine $(\mathrm{p}<0.05)$ (Table 1$)$.

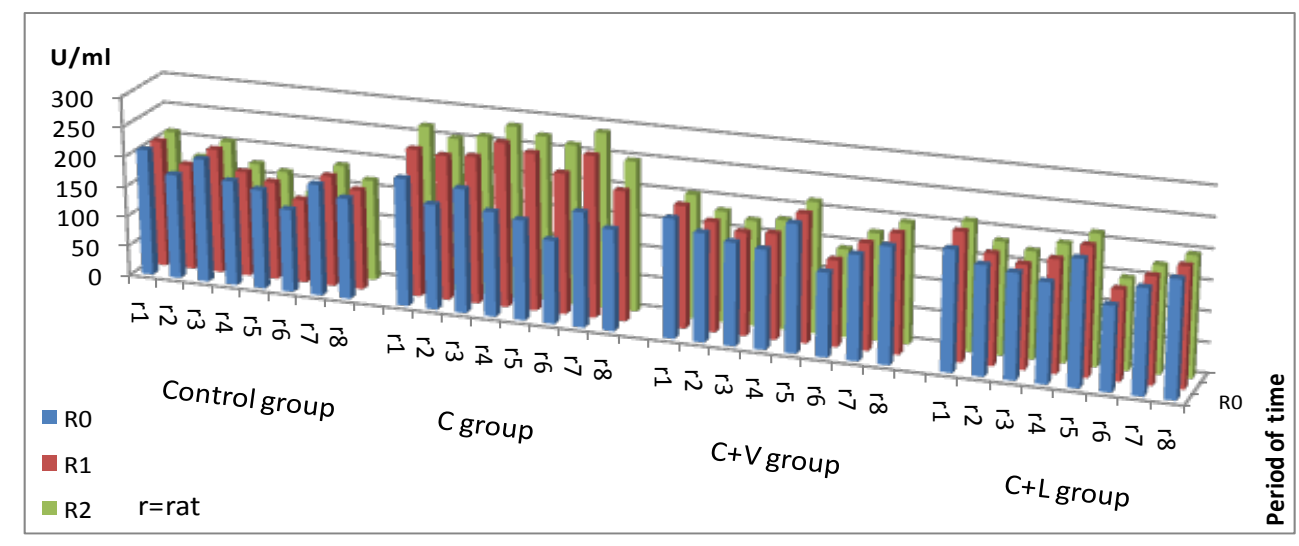

Figure 1. Individual SOD values recorded in the studied groups.

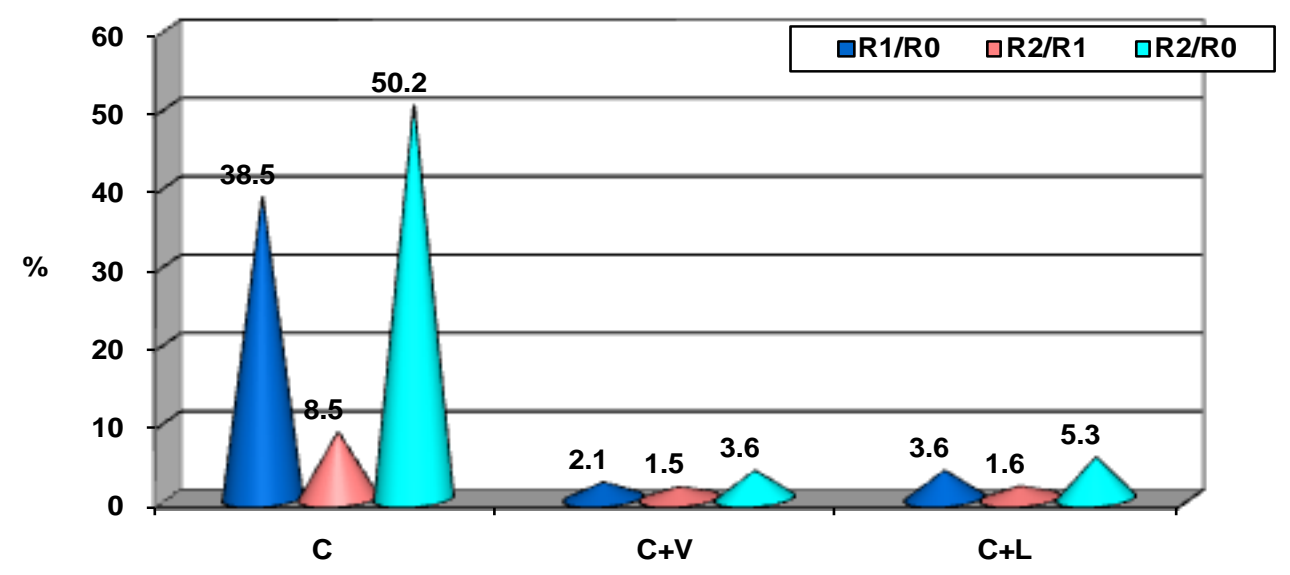

Figure 2. Percentage differences of the average SOD values compared to R0. 
Table 1. Statistical differences between average values of SOD.

\begin{tabular}{|c|c|c|c|c|}
\hline Moment & Group & Control Group $(n=10)$ & $C(n=10)$ & $C+V(n=10)$ \\
\hline \multirow{3}{*}{ Ro } & $C(\mathrm{n}=8)$ & $\begin{array}{l}\mathrm{t}=0.05 \\
\mathrm{p}>0.05\end{array}$ & - & \\
\hline & $C+V(n=8)$ & $\begin{array}{l}\mathrm{t}=0.01 \\
\mathrm{p}>0.05\end{array}$ & $\begin{array}{l}\mathrm{t}=0.06 \\
\mathrm{p}>0.05\end{array}$ & - \\
\hline & $C+L(n=8)$ & $\begin{array}{l}t=00.03 \\
p>0.05\end{array}$ & $\begin{array}{l}\mathrm{t}=0.01 \\
\mathrm{p}>0.05\end{array}$ & $\begin{array}{l}\mathrm{t}=0.05 \\
\mathrm{p}>0.05\end{array}$ \\
\hline \multirow{3}{*}{ R1 } & $C(\mathrm{n}=8)$ & $\begin{aligned} \mathrm{t} & =6.49 \\
\mathrm{p} & <0.001\end{aligned}$ & - & \\
\hline & $C+V(n=8)$ & $\begin{array}{l}\mathrm{t}=0.31 \\
\mathrm{p}>0.05\end{array}$ & $\begin{array}{c}\mathrm{t}=6.11 \\
\mathrm{p}<0.001\end{array}$ & - \\
\hline & $C+L(n=8)$ & $\begin{array}{l}\mathrm{t}=0.01 \\
\mathrm{p}>0.05\end{array}$ & $\begin{array}{c}\mathrm{t}=6.15 \\
\mathrm{p}<0.001\end{array}$ & $\begin{array}{l}\mathrm{t}=0.30 \\
\mathrm{p}>0.05\end{array}$ \\
\hline \multirow{3}{*}{$\mathbf{R} 2$} & $C(\mathrm{n}=8)$ & $\begin{aligned} \mathrm{t} & =9.23 \\
\mathrm{p} & <0.001\end{aligned}$ & - & \\
\hline & $C+V(n=8)$ & $\begin{array}{l}\mathrm{t}=0.54 \\
\mathrm{p}>0.05\end{array}$ & $\begin{aligned} t & =9.03 \\
p & <0.001\end{aligned}$ & - \\
\hline & $C+L(n=8)$ & $\begin{array}{l}\mathrm{t}=0.86 \\
\mathrm{p}>0.05\end{array}$ & $\begin{aligned} \mathrm{t} & =8.76 \\
\mathrm{p} & <0.001\end{aligned}$ & $\begin{array}{l}\mathrm{t}=0.03 \\
\mathrm{p}>0.05\end{array}$ \\
\hline
\end{tabular}

Considering the other antioxidant enzyme, evolution of GPx levels and variance during the experiment is presented in Figure 3.

The most homogeneous range values within control group was registered at the end of the experiment (3.60 $\mathrm{CV} \%$ ). The variance of the GPx values in the study groups ranged between 1.86 to 9.01 percentage, the most homogeneous values being recorded in group IV $(\mathrm{C}+\mathrm{L})$ at the beginning of the experiment $(1.87 \mathrm{CV} \%)$, in group III (C + V) after 1 month (2.89 CV\%), and group II(C) at the end of the experiment (3.71 CV\%).

The highest individual values of GPx were found in group II fed exclusively by cholesterol (Figure 3).

Considering the moment of investigation, the average GPx values recorded the following percentage increases (Figure 4):

Group II recorded percentage increase in average GPx values of $9.6 \%$ and $30.8 \%$, after one and two months respectively (compared to the initial moment), whereas group III registered just a slight increase of $1.9 \%$ after one month and $4.6 \%$ at the end of the experiment. In group IV, the percentage increase in average GPx values was $3.6 \%$ after one month and $5.6 \%$ at the end of the experiment.

No significant differences between mean GPx values were recorded within study groups or between them and the control group, at the beginning of the study (R0) ( $p>0.05)$. Groups II and IV registered increased mean GPx values compared to control, after one and two months from the beginning of the experiment $(p<0.05)$, group II having higher values when compared to mean levels of group III $(\mathrm{p}<0.05)$.

Moreover, average GPx values were significantly increased at the end of the experimental period in all groups, compared to control ( $\mathrm{p}<0.05)$, mean values of group II being significantly higher compared to groups with essential amino acids supplemented ( $<<0.001)$. There were no significant differences after sixty days, in the average GPx activities between the groups III and IV ( $>>0.05$ ), and thus, the two essential aminoacids determined comparable antioxidant effects up to the end of experimental period (Table 2).

\section{Discussions}

Atherosclerosis represents one of the disorders whereas lipids and proteins are oxidized in the blood vessel's wall, with the advent of an increased level of oxidative stress, recognized as important component of the occurrence of cardiovascular diseases and particularly atherosclerosis. Oxidative stress is due to an excessive formation of highly reactive molecules such as ROS (reactive oxygen species) and RNS (reactive nitrogen species) or their insufficient removal [12]. Being involved in various cellular mechanisms, ROS have a positive impact on the body, when they do not accumulate excessively.

In the early stages of atherosclerotic disease, inflammatory cells and possible other cell types, produce reactive oxygen species that destroy the vasoprotective NO (nitric oxide). In addition to the decreased gene expres- 


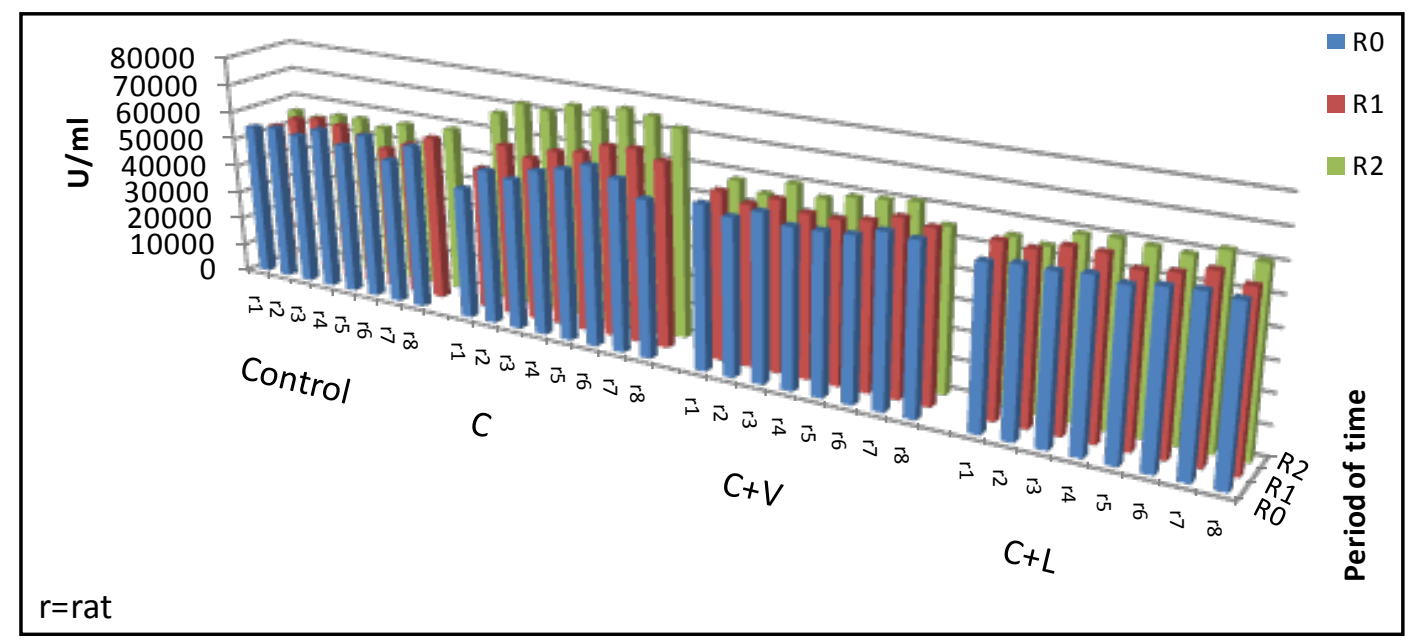

Figure 3. Individual GPx values in the studied groups.

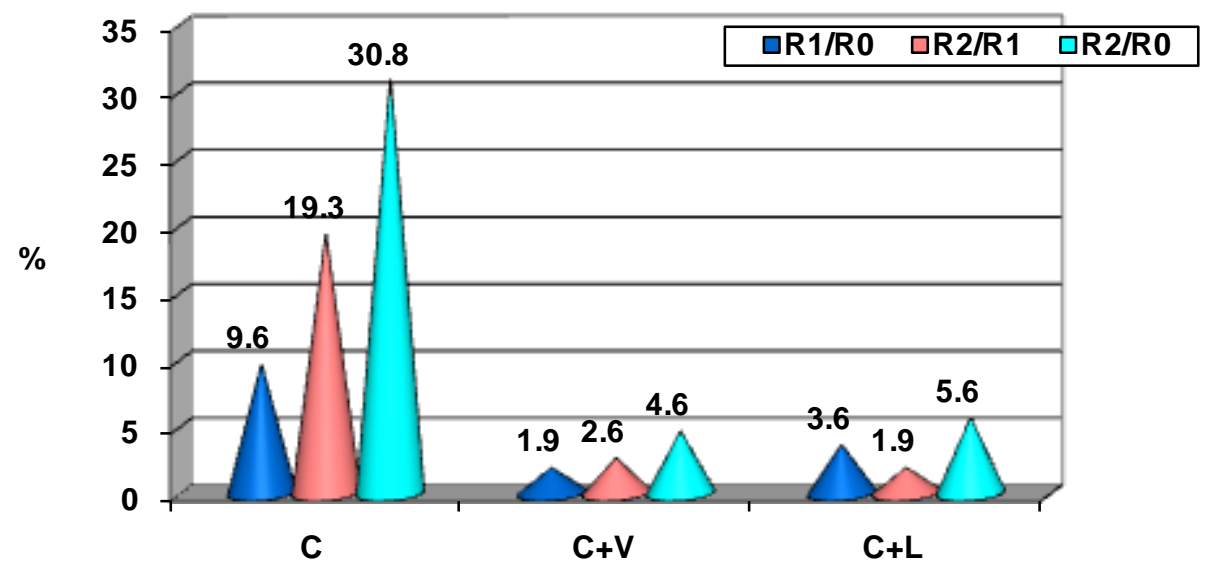

Figure 4. Percentage difference of mean GPx values.

Table 2. Statistical differences between mean GPx values.

\begin{tabular}{|c|c|c|c|c|}
\hline Moment & Group & Control Group $(n=10)$ & $C(n=10)$ & $C+V(n=10)$ \\
\hline \multirow{3}{*}{ Ro } & $\begin{array}{c}C \\
(n=8)\end{array}$ & $\begin{array}{l}\mathrm{t}=0.10 \\
\mathrm{p}>0.05\end{array}$ & - & \\
\hline & $C+V(n=8)$ & $\begin{aligned} t & =023 \\
p & >0.05\end{aligned}$ & $\begin{array}{l}\mathrm{t}=0.02 \\
\mathrm{p}>0.05\end{array}$ & - \\
\hline & $C+L(n=8)$ & $\begin{array}{l}\mathrm{t}=0.42 \\
\mathrm{p}>0.05\end{array}$ & $\begin{array}{l}\mathrm{t}=0.11 \\
\mathrm{p}>0.05\end{array}$ & $\begin{array}{c}t=023 \\
p>0.05\end{array}$ \\
\hline \multirow{3}{*}{$\mathbf{R} 1$} & $\begin{array}{c}C \\
(n=8)\end{array}$ & $\begin{array}{l}\mathrm{t}=2.76 \\
\mathrm{p}<0.05\end{array}$ & - & \\
\hline & $C+V(n=8)$ & $\begin{array}{l}\mathrm{t}=1.41 \\
\mathrm{p}>0.05\end{array}$ & $\begin{array}{l}\mathrm{t}=2.16 \\
\mathrm{p}<0.05\end{array}$ & - \\
\hline & $C+L(n=8)$ & $\begin{array}{l}\mathrm{t}=2.55 \\
\mathrm{p}<0.05\end{array}$ & $\begin{array}{l}t=1.62 \\
p>0.05\end{array}$ & $\begin{array}{l}\mathrm{t}=1.45 \\
\mathrm{p}>0.05\end{array}$ \\
\hline \multirow{3}{*}{$\mathbf{R} 2$} & $\begin{array}{c}C \\
(n=8)\end{array}$ & $\begin{array}{l}\mathrm{t}=14.23 \\
\mathrm{p}<0.001\end{array}$ & - & \\
\hline & $C+V(n=8)$ & $\begin{array}{l}\mathrm{t}=2.25 \\
\mathrm{p}<0.05\end{array}$ & $\begin{array}{l}\mathrm{t}=11.61 \\
\mathrm{p}<0.001\end{array}$ & - \\
\hline & $C+L(n=8)$ & $\begin{array}{l}\mathrm{t}=2.64 \\
\mathrm{p}<0.05\end{array}$ & $\begin{array}{l}\mathrm{t}=10.23 \\
\mathrm{p}<0.001\end{array}$ & $\begin{array}{l}\mathrm{t}=0.57 \\
\mathrm{p}>0.05\end{array}$ \\
\hline
\end{tabular}


sion of enzymes that produce NO, it is also disturbed the enzymatic activity, which contributes to an increased oxidative stress in atherosclerosis [13]. In the late stages of the disease not only a decreased activity of NO can be noted, but also a reduction in the reception and of cGMP signals, strongly associated with neointimal proliferation and vascular dysfunctions [14]. Overexpression of enzyme eNOS (endothelial nitric oxide synthase) which produces NO may accelerate the disease progression; therefore, more researches are focused on controlling eNOS activity and preventing NO inactivation by oxidative stress [15].

Recent studies have demonstrated that an impaired NO production may play an important role in the pathogenesis of cardiovascular diseases such as hypertension, atherosclerosis, post-ischemic lack of oxygen, acute inflammation and myocardial depression associated with septic shock [16]-[18]. Other studies have shown that there is an age-related NO activity decrease, independent of the presence of atherosclerotic disease [19] [20].

In our study, the high-fat diet disturbs the lipid metabolism, the largest individual cholesterol values being found in group receiving only cholesterol (C). Although at first determination, no significant differences between mean cholesterol values between groups II, III, IV and the control group ( $p>0.05$ ) were highlighted, after one month and especially at the end of the experiment, average values of this parameter were significantly higher in all groups compared with controls $(\mathrm{p}<0.001)$. Of these, significantly higher values were obtained in the group II who received only cholesterol (C) compared to the group III receiving valine (C + V) or IV receiving leucine $(\mathrm{R}+\mathrm{L})(\mathrm{p}<0.001)$; this demonstrates a beneficial effect of the administration of the two amino acids.

Some authors have shown that endothelial dysfunction may be improved by changing lifestyle in terms of a strictly hygienic-dietary diet. Regular physical exercises, smoking cessation, reduction of alcohol consumption and high-fat diet, also have beneficial effects. Dietary supplementation with antioxidant vitamins and folic acid, omega-3 fatty acids and other protective compounds is associated with reduction of cardiovascular risk events and may also affect other coronary risk factors [21] [22]. These strategies and habits may be supplemented by pharmacological therapy, targeted on pathophysiological processes that cause endothelial dysfunction. Thus, reduced lipid, hypoglycemic, anti-inflammatory and hormone replacement therapy result in improved vasodilatatory ability, reduction in lipid peroxidation and reduced leukocyte adhesion to the endothelium.

Our body has various mechanisms of defense from oxygen free radical toxicity: by enzymatic antioxidant mechanisms in which are involved enzymes as superoxide dismutase-SOD, glutathione peroxidase GPx, glutathione reductase-GR and catalase and/or by non-enzymatic antioxidants such as vitamins, albumin, bilirubin, and many others). It is known that antioxidant enzymes reduce the levels of lipid peroxides as well as hydrogen peroxide. Also they are important factors in preventing lipid peroxidation and maintaining the structure and function of biologic membranes.

SOD catalyses the dismutation of peroxide to hydrogen peroxide. Numerous studies revealed significant SOD elevations in disorders characterized by an increased oxidative stress. The expression of SOD from the erythrocytes is not always related to the severity of disease expression, but rather, to the protective response of the body cells to released inflammatory cytokines of the altered tissue. When ROS are moderately increased, the induced changes are reversible.

The present study revealed the highest individual values of SOD in group II receiving only cholesterol. At the beginning of the study there were not significant differences between mean values of SOD recorded in groups II, III and IV or between them and the control group $(\mathrm{p}>0.05)$. After 1 month and at the end of the experiment, the average values of SOD were significantly higher in group II compared with controls $(\mathrm{p}<0.001)$ and compared to group III that received valine $(C+V)$ and group IV that received leucine $(C+L)(p<0.001)$. At the end of the experiment, there were no significantly differences between SOD values registered in group II and IV ( $\mathrm{p}<$ $0.05)$.

GPx catalyzes the oxidation of glutathione. In our study, the highest individual values of GPx were found in the group II receiving only cholesterol. At the beginning of the study there were no significant differences between mean values of GPx registered between groups II, III and IV and between them and the control group ( $>$ $0.05)$. After one month were registered higher average values of GPx in groups II and IV ( $<<0.05)$ compared with controls; in group II compared with group III, the values of this parameter were significantly higher ( $<$ $0.05)$. At the end of the study, mean GPx values were significantly increased in all groups compared with controls $(\mathrm{p}<0.05)$. Mean GPx in group II were significantly higher compared with group III $(\mathrm{C}+\mathrm{V})$ and IV $(\mathrm{C}+\mathrm{L})$ $(p<0.001)$. These findings regarding SOD and GPx values suggest a possible antioxidant capacity of valine and leucine with subsequent positively intervention in the pathogenic mechanism of atherosclerosis.

ROS are highly cytotoxic, and sometimes the induced changes may be irreversible, causing cell apoptosis. An 
excess of ROS production causes dysfunctions in the cell membranes, conformational changes of proteins, enzymes, resulting in DNA chains break. Due to their rich content in polyunsaturated fatty acids, cell membranes display a high susceptibility to the action of ROS, undergoing changes in fluidity and permeability [23] [24].

Recent studies have suggested that ROS may be key components of the signaling pathways, being responsible for induction or suppression of cell proliferation as well as the onset or inhibition of apoptosis. The human body still has enzymatic (SOD, glutathione peroxidase, catalase) and non-enzymatic mechanisms (glutathione, vitamins A, B, C, E) to prevent the harmful action of ROS, by maintaining a low level of peroxidation process. The antioxidant systems are metabolically interconnected and act together completing each other, inhibition of free radical generation or degradation of the already synthesized radicals being among the main mechanisms of their action [25] [26].

Branched chain aliphatic amino acids (i.e. valine, leucine, and isoleucine) are the most hydrophobic amino acids that play a crucial role in determining the structure of globular proteins, as well as the interaction between transmembrane domains of the protein and membrane phospholipids. However, they do not behave quite similar, in terms of protein secondary structure valine and isoleucine having a definite preference for beta-type structure, while leucine has a higher preference for alpha-helix structure. The occurrence of branched chain amino acids in nature can be attributed mainly to their role in protein structure, and not to secondary metabolic involvement [27]. Experimental studies have shown that valine or isoleucine deficiency has similar effects on reducing fat mass in a manner similar to those observed during deprivation of leucine. Animals fed with a diet deficient in these amino acids have significant changes in lipid metabolism, as demonstrated by suppression of lipogenesis in the liver and increase fat mobilization in white adipose tissue. Central nervous system plays an important role in regulating fat loss concomitantly with leucine deprivation, providing thus important new insights on the impact of leucine upon central regulation of the energetic balance [28]. Increased levels of branched chain amino acids levels in obesity have been reported since the 1960s. These reports are of great interest because of the role of these compounds in regulating satiety, leptin, glucose, cellular signals, intra-abdominal and body weight [29] [30].

Growing evidence from animal studies shows that mainly essential amino acids play important roles in multiple signaling pathways, thereby regulating gene expression, intracellular protein turnover, nutrient metabolism, and oxidative defense. Some studies in the field stated the main role of oxidative stress in pathogenesis of atherosclerosis, the imbalance between pro- and anti-oxidants contributing in a decisive manner within regulation of proinflammatory gene expression, very probably NF- $\kappa \beta$ being one of the mediators [31] [32].

Considering the choice of adding valine and leucine to the hypercholesterolemiant diet, our study suggests that modulation of the oxidative stress mediated through antioxidant enzyme levels can be partly explained by leucine's ability to convert to its metabolite $\beta$-hydroxyl- $\beta$-methyl butyrate (HMB), which has previously been revealed to modulate protein turnover and inhibit expression of NF- $\kappa \beta$. Furthermore, modulation of protein synthesis through NF- $\kappa \beta$ inhibition results in reduction of inflammatory response and thus of atherosclerotic events [33]. NF- $\kappa \beta$ is therefore a central mediator of vascular inflammation that turns it into an attractive therapeutic target in cardiovascular disorders management.

Amino acids are essential precursors for the synthesis of many molecules with a major impact upon body homeostasis [34] [35]. Dietary supplementation with one or a mixture of amino acids may be beneficial in improving health problems related to a variety of disorders, in which oxidative stress is an important pathogenetic link, therefore, any study of these changes in the field brings important insights for the understanding and management of various diseases.

\section{Conclusion}

Our experimental study designed to determine the changes in oxidative status after supplementation of the animals high-fat diet with two essential branched amino acids, revealed that both, valine and leucine, have a direct effect on reducing SOD and GPx values. This observation suggests an antioxidant capacity of valine and leucine with subsequent positive intervention in pathogenic mechanism of atherosclerosis. Comparing the activity of the two essential amino acids, we concluded that valine and leucine were not significantly different related to the speed and efficiency of their intervention in improving the biochemical antioxidant parameters. The mechanism behind these changes remains to be further investigated, as it was dependent on changes in oxidative status. This experimental study brings evidences supporting the protective effects of dietary amino acid supplementation, which open perspectives for new therapies to prevent the occurrence of atherosclerosis. 


\section{References}

[1] Channon, K. (2006) The Endothelium and the Pathogenesis of Atherosclerosis. Medicine, 5, 173-177. http://dx.doi.org/10.1383/medc.2006.34.5.173

[2] Hahn, C. and Schwartz, M.A. (2008) The Role of Cellular Adaptation to Mechanical Forces in Atherosclerosis. Arteriosclerosis, Thrombosis, and Vascular Biology, 12, 2101-2107. http://dx.doi.org/10.1161/ATVBAHA.108.165951

[3] Linic, I.S., Sosa, I., Kovacevic, M., Ivancic, A., Trobonjaca, Z., Ledic, D., Grubesic, A., Dvornik, S. and Stifter, S. (2013) Predicting Carotid Restenosis by Comparison of Plaque MCP-1 mRNA Expression and Serum Levels. Medical Hypotheses, 80, 26-28. http://dx.doi.org/10.1016/j.mehy.2012.09.022

[4] Muller, G. And Morawietz, H. (2009) NAD(P)H Oxidase and Endothelial Dysfunction. Hormone and Metabolic Research, 2, 152-158. http://dx.doi.org/10.1055/s-0028-1086023

[5] Ginnan, R., Guikema, B.J., Halligan, K.E., Singer, H.A. and Jourd'heuil, D. (2008) Regulation of Smooth Muscle by Inducible Nitric Oxide Synthase and NADPH Oxidase in Vascular Proliferative Diseases. Free Radical Biology and Medicine, 7, 1232-1245. http://dx.doi.org/10.1016/j.freeradbiomed.2007.12.025

[6] Madamanchi, N.R., Tchivilev, I. and Runge, M. (2006) Genetic Markers of Oxidative Stress and Coronary Atherosclerosis. Current Atherosclerosis Reports, 8, 177-183. http://dx.doi.org/10.1007/s11883-006-0071-3

[7] Thomas, S.R., Witting, P.K. and Drummond, G.R. (2008) Redox Control of Endothelial Function and Dysfunction: Molecular Mechanisms and Therapeutic Opportunities. Antioxid Redox Signal, 10, 1713-1765. http://dx.doi.org/10.1089/ars.2008.2027

[8] Cojocaru, E., Zamfir, C., Zamosteanu, N., Trandafirescu, M. and Cotuţiu, C. (2012) Effects of Branched Chain Aminoacids upon HDL-Cholesterol in Experimental Animals Feeded by Hypercholesterolemiant Diet. Revista medicoChirurgicala a Societatii de Medici si Naturalisti din Iasi, 1, 200-206.

[9] National Advisory Committee for Laboratory Animal Research (2004) Guidlines on the Care and Use of Animals for Scientific Purposes.

[10] Woolliams, J.A., Wiener, G., Anderson, P.H. and Mc Murray, C.H. (1983) Variation in the Activities of Glutathione Peroxidase and Superoxide Dismutase and in the Concentration of Copper in the Blood in Various Breed Crosses of Sheep. Research in Veterinary Science, 34, 253-256.

[11] Paglia, D.E. and Valentine, W.N. (1967) Studies on the Quantitative and Qualitative Characterization of Erythrocyte Glutathione Peroxidase. Journal of Laboratory and Clinical Medicine, 70, 158-169.

[12] Förstermann, U. (2008) Oxidative Stress in Vascular Disease: Causes, Defense Mechanisms and Potential Therapies. Nature Reviews Cardiology, 5, 338-349. http://dx.doi.org/10.1038/ncpcardio1211

[13] Yang, Z.H. and Ming, X.F. (2006) Endothelial Arginase: A New Target in Atherosclerosis. Current Hypertension Reports, 8, 54-59. http://dx.doi.org/10.1007/s11906-006-0041-8

[14] Melichar, V.O., Behr-Roussel, D., Zabel, U., Uttenthal, L.O., Rodrigo, J., Rupin, A., Verbeuren, T.J., Kumar, H.S.A. and Schmidt, H.H. (2004) Reduced cGMP Signaling Associated with Neointimal Proliferation and Vascular Dysfunction in Late-Stage Atherosclerosis. Proceedings of the National Academy of Sciences of the United States of America, 101, 16671-16676. http://dx.doi.org/10.1073/pnas.0405509101

[15] Yang, Z.H. and Ming, X.F. (2006) Recent Advances in Understanding Endothelial Dysfunction in Atherosclerosis. Clinical Medicine \& Research, 4, 53-65. http://dx.doi.org/10.3121/cmr.4.1.53

[16] Landmesser, U. and Drexler, H. (2007) Endothelial Function and Hypertension. Current Opinion in Cardiology, 22, 316-320. http://dx.doi.org/10.1097/HCO.0b013e3281ca710d

[17] Paravicini, T.M. and Touyz, R.M. (2008) NADPH Oxidases, Reactive Oxygen Species, and Hypertension: Clinical Implications and Therapeutic Possibilities. Diabetes Care, 31, S170-S180. http://dx.doi.org/10.2337/dc08-s247

[18] Touyz, R.M. and Briones, A.M. (2011) Reactive Oxygen Species and Vascular Biology: Implications in Human Hypertension. Hypertension Research, 34, 5-14. http://dx.doi.org/10.1038/hr.2010.201

[19] Al-Shaer, M.H., Choueiri, N.E., Correia, M.L., Sinkey, C.A., Barenz, T.A. and Haynes, W.G. (2006) Effects of Aging and Atherosclerosis on Endothelial and Vascular Smooth Muscle Function in Humans. International Journal of Cardiology, 109, 201-206. http://dx.doi.org/10.1016/j.ijcard.2005.06.002

[20] Walsh, T., Donnelly, T. and Lyons, D. (2009) Impaired Endothelial Nitric Oxide Bioavailability: A Common Link between Aging, Hypertension, and Atherogenesis? Journal of the American Geriatrics Society, 57, 140-145. http://dx.doi.org/10.1111/j.1532-5415.2008.02051.x

[21] Rush, J.W., Denniss, S.G. and Graham, D.A. (2005) Vascular Nitric Oxide and Oxidative Stress: Determinants of Endothelial Adaptations to Cardiovascular Disease and to Physical Activity. Canadian Journal of Applied Physiology, 30, 442-474. http://dx.doi.org/10.1139/h05-133 
[22] Di Francescomarino, S., Sciartilli, A., Di Valerio, V., Di Baldassarre, A. and Gallina, S. (2009) The Effect of Physical Exercise on Endothelial Function. Sports Medicine, 39, 797-812. http://dx.doi.org/10.2165/11317750-000000000-00000

[23] Suvorava, T. and Kojda, G. (2009) Reactive Oxygen Species as Cardiovascular Mediators: Lessons from EndothelialSpecific Protein Overexpression Mouse Models. Biochimica et Biophysica Acta, 1787, 802-810. http://dx.doi.org/10.1016/j.bbabio.2009.04.005

[24] Higashi, Y., Noma, K., Yoshizumi, M. and Kihara, Y. (2009) Endothelial Function and Oxidative Stress in Cardiovascular Diseases. Circulation Journal, 73, 411-418. http://dx.doi.org/10.1253/circj.CJ-08-1102

[25] Niki, E. (2010) Assessment of Antioxidant Capacity in Vitro and in Vivo. Free Radical Biology and Medicine, 49, 503515. http://dx.doi.org/10.1016/j.freeradbiomed.2010.04.016

[26] Niki, E., Omata, Y., Fukuhara, A., Saito, Y. and Yoshida, Y. (2008) Assessment of Radical Scavenging Capacity and Lipid Peroxidation Inhibiting Capacity of Antioxidant. Journal of Agricultural and Food Chemistry, 56, 8255-8260. http://dx.doi.org/10.1021/jf800605x

[27] Brosnan, J.T. and Brosnan, M.E. (2006) Branched-Chain Amino Acids: Enzyme and Substrate Regulation. Journal of Nutrition, 136, 207S-211S.

[28] Cheng, Y., Zhang, Q., Meng, Q., Xia, T., Huang, Z., Wang, C., Liu, B., Chen, S., Xiao, F., Du, Y. and Guo, F. (2011) Leucine Deprivation Stimulates Fat Loss via Increasing CRH Expression in the Hypothalamus and Activating the Sympathetic Nervous System. Molecular Endocrinology, 25, 1624-1635. http://dx.doi.org/10.1210/me.2011-0028

[29] Arakawa, M., Masaki, T., Nishimura, J., Seike, M. and Yoshimatsu, H. (2011) The Effects of Branched-Chain Amino Acid Granules on the Accumulation of Tissue Triglycerides and Uncoupling Proteins in Diet-Induced Obese Mice. Endocrine Journal, 58, 161-170. http://dx.doi.org/10.1507/endocrj.K10E-221

[30] She, P., Van Horn, C., Reid, T., Hutson, S.M., Cooney, R.N. and Lynch, C.J. (2007) Obesity-Related Elevations in Plasma Leucine Are Associated with Alterations in Enzymes Involved in Branched-Chain Amino Acid Metabolism. American Journal of Physiology-Endocrinology and Metabolism, 293, E1552-E1563. http://dx.doi.org/10.1152/ajpendo.00134.2007

[31] Mârţu, S., Nănescu, S.E. and Constantin, L. (2006) Stress Effects on Immune Mechanisms in Periodontal Disease. Romanian Dentistry Journal, 1, 35-38.

[32] Kim, M.K., Kolch, W. and Cho, K.H. (2009) Multiple Roles of the NF- $\kappa$ B Signaling Pathway Regulated by Coupled Negative Feedback Circuits. FASEB Journal, 23, 2796-2802. http://dx.doi.org/10.1096/fj.09-130369

[33] Gilmore, T.D. (2006) Introduction to NF- $\kappa$ B: Players, Pathways, Perspectives. Oncogene, 25, 6680-6684. http://dx.doi.org/10.1038/sj.onc.1209954

[34] Harris, R.A., Joshi, M. and Jeoung, N.H. (2004) Mechanisms Responsible for Regulation of Branched-Chain Amino Acid Catabolism. Biochemical and Biophysical Research Communications, 313, 391-396. http://dx.doi.org/10.1016/j.bbrc.2003.11.007

[35] Wu, G.Y. (2009) Amino Acids: Metabolism, Functions, and Nutrition. Amino Acids, 37, 1-17. http://dx.doi.org/10.1007/s00726-009-0269-0 
Scientific Research Publishing (SCIRP) is one of the largest Open Access journal publishers. It is currently publishing more than 200 open access, online, peer-reviewed journals covering a wide range of academic disciplines. SCIRP serves the worldwide academic communities and contributes to the progress and application of science with its publication.

Other selected journals from SCIRP are listed as below. Submit your manuscript to us via either submit@scirp.org or Online Submission Portal.
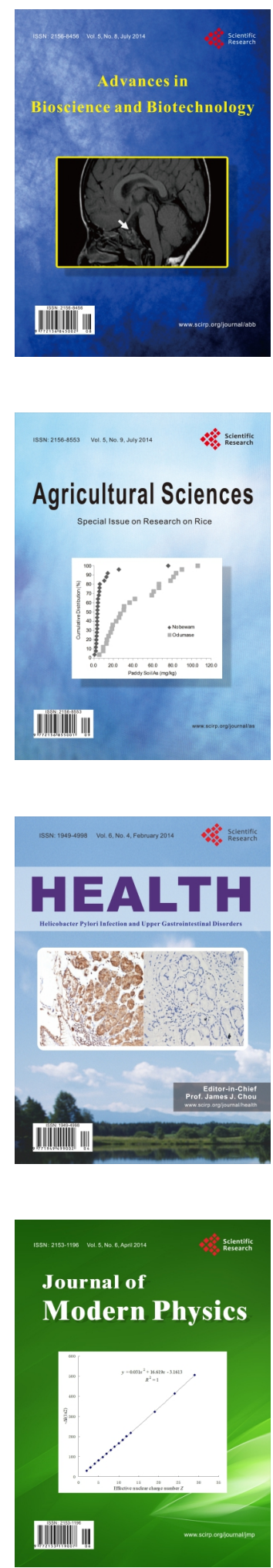
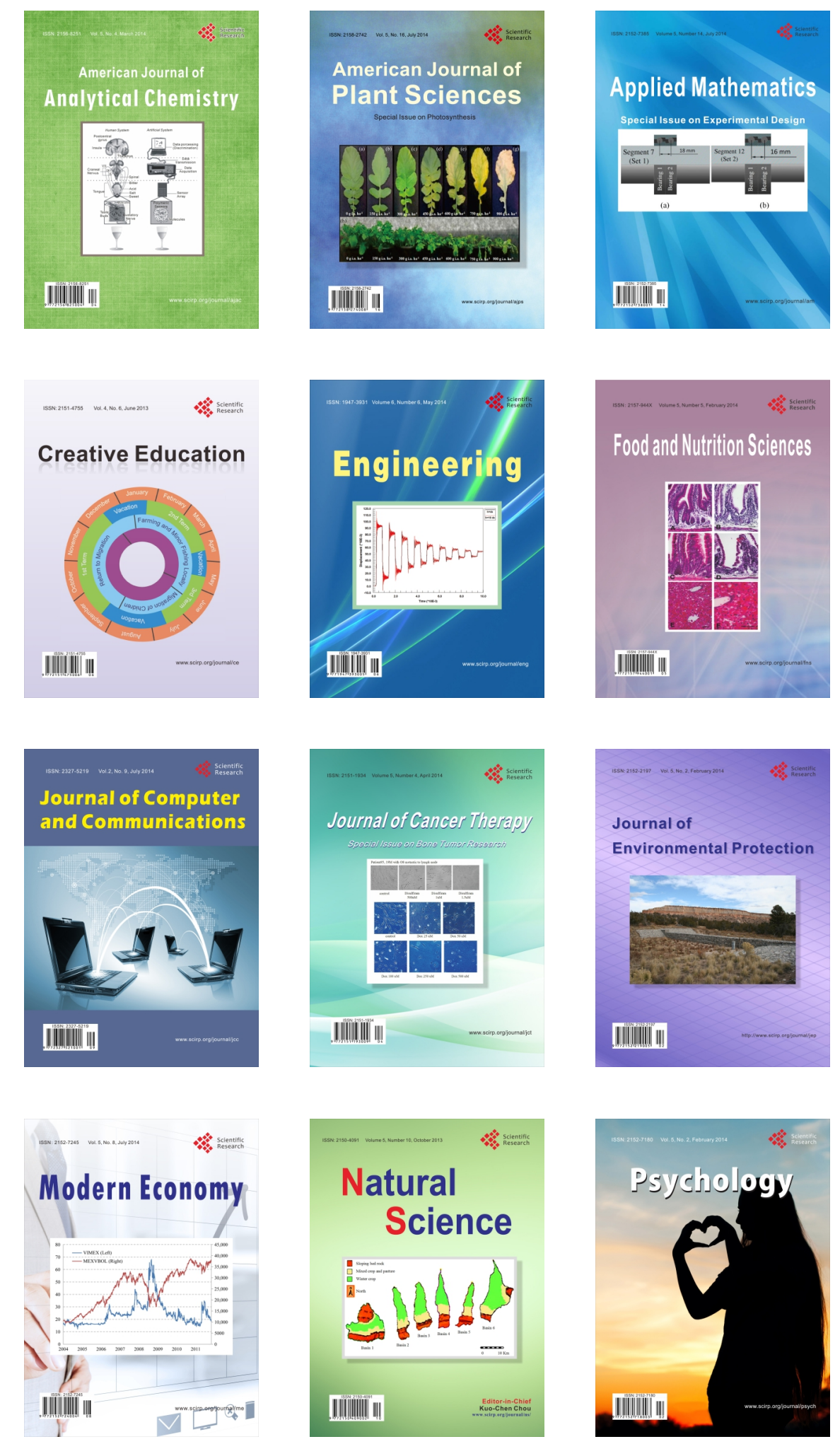